Review Article

\title{
Radix Astragali-Based Chinese Herbal Medicine for Oxaliplatin-Induced Peripheral Neuropathy: A Systematic Review and Meta-Analysis
}

\author{
Bo Deng, Liqun Jia, and Zhiqiang Cheng \\ Department of Oncology of Integrative Chinese and Western Medicine, China-Japan Friendship Hospital, Beijing 100029, China \\ Correspondence should be addressed to Liqun Jia; liqun-jia@hotmail.com
}

Received 25 May 2016; Accepted 7 August 2016

Academic Editor: Wenyi Kang

Copyright @ 2016 Bo Deng et al. This is an open access article distributed under the Creative Commons Attribution License, which permits unrestricted use, distribution, and reproduction in any medium, provided the original work is properly cited.

Background. Treatment of chemotherapy-induced peripheral neuropathy (CIPN) remains a big challenge for oncologists. The aim of this study is to evaluate the effects of Radix Astragali- (RA-) based Chinese herbal medicine in the prevention and treatment of oxaliplatin-induced peripheral neuropathy, including the incidence and grading of neurotoxicity, effective percentage, and nerve conduction velocity. Methods. All randomized controlled trials (RCTs) were found using PubMed, Cochrane, Springer, China National Knowledge Infrastructure (CNKI), and Wanfang Database of China Science Periodical Database (CSPD) by keyword search. Meta-analysis was conducted using RevMan 5.0. Results. A total of 1552 participants were included in 24 trials. Meta-analysis showed the incidence of all-grade neurotoxicity was significantly lower in experimental groups and high-grade neurotoxicity was also significantly less. Effective percentage was significantly higher and sensory nerve conduction velocity was improved significantly, but changes in motor nerve conduction velocity were not statistically significant. No adverse events associated with RAbased intervention were reported. Conclusion. RA-based intervention may be beneficial in relieving oxaliplatin-induced peripheral neuropathy. However, more double-blind, multicenter, large-scale RCTs are needed to support this theory. Trial Registration. PROSPERO International prospective register of systematic reviews has registration number CRD42015019903.

\section{Introduction}

Chemotherapy-induced peripheral neuropathy (CIPN) results from toxic effects of chemotherapy drugs predominantly affecting the peripheral nervous system. The associated pain of CIPN can be extremely disabling, with a marked impact on quality of life (Qol), functions of daily living, and increases the risks of noncompliance with cancer treatment [1]. Oxaliplatin (OXAL), a third-generation platinum-based compound, has become pivotal for the therapy of metastatic colorectal cancer and other malignancies including lung, breast, and ovarian cancers $[2,3]$. However, OXAL induced chronic neurotoxicity occurs in $63.6 \%$ or more of patients, which limited the dosing of OXAL [4].

Radix Astragali (the root of Astragalus mongholicus Bge. or Astragalus membranaceus Bge.) has been used as one of the primary tonic herbs in traditional Chinese and Japanese Kampo medicine. Recently, Radix Astragali (Huangqi, in
Chinese) is being widely used, orally or topically, and alone or in combination with western conventional medicine to relieve CIPN. Multiple randomized clinical trials have suggested that Radix Astragali- (RA-) based intervention can reduce symptoms, improve Qol and immunologic function, increase plasma nerve growth factor (NGF) levels, and delay the progression of CIPN [5-28]. In vivo RA-based prescription (Huangqi Guizhi Wuwu Decoction) can effectively relieve pain and improve sciatic nerve conduction velocity and function in rats with CIPN $[29,30]$. Its mechanism may be related to downregulating NR2B expression in L46 lumbar spinal segments and upregulating pNF-H protein levels in dorsal root ganglia [30]. However, no systematic review to date has reported effects of RA-based intervention on OXAL induced peripheral neuropathy. In this metaanalysis, the effectiveness and safety of RA-based intervention for preventing and treating OXAL induced peripheral neuropathy are evaluated for the first time. 


\section{Methods}

Ethics data for this study were acquired through previously published work; no patient or hospital data were accessed. Therefore, written consent and institutional ethical review were not required for this research.

2.1. Database and Search Strategies. The electronic databases of MEDLINE (1982-2015), Cochrane Controlled Trials (2015, Issue 12), Springer (1997-2015), China National Knowledge Infrastructure (CNKI) database (1997-2015), and Wanfang Database of China Science Periodical Database (CSPD) (1998-2015) were searched by using keywords of "Neurotoxicity", "Oxaliplatin" "Astragali", or "Huangqi”, without language limitation. Reference lists from trials selected by electronic searching were hand searched. All of those searches ended before January 2016.

2.2. Inclusion Criteria. All randomized controlled trials (RCTs) investigating the effects of RA-based Chinese herbal medicine for preventing and treating OXAL induced peripheral neuropathy will be eligible for inclusion.

2.2.1. Types of Participants. All adult patients (18 years and older, no upper age limit) with a treatment of OXAL will be considered for this review. The participants had to conform to the following diagnostic criteria.

(1) The patient was clearly diagnosed malignant by pathology or cytology.

(2) The patient was treated by OXAL, FOLFOX (OXAL + 5-fluorouracil + calcium folinate), or XELOX (OXAL + capecitabine).

(3) Age, gender, stages, and pathological types between the groups were balanced and comparable.

2.2.2. Types of Interventions. RA-based interventions included single herb (including extracts from RA) and a compound of several herbs, irrespective of dosage form (e.g., oral decoction or lotion). The mode of delivery (e.g., oral, topical administration or intravenous) was not restricted. Relative high dose RA (monarch drug) should be included in the prescription and regimen of herbs was not restricted.

The control interventions were placebo, no intervention, or conventional treatment such as mecobalamin, $\mathrm{Ca} / \mathrm{Mg}$ infusions, or reduced glutathione. We also included trials of RA-based prescription plus conventional medicine versus the same conventional medicine alone.

\subsection{Types of Outcome Measures}

Grading of CIPN. Primary outcome was the grading of CIPN in at least 1 chemotherapy cycle, but preferably in 4 cycles of chemotherapy. We considered Levi's grade [31], World Health Organization (WHO) grade [32] or National Cancer Institute common terminology criteria for adverse events (NCI-CTCAE) for the clinical grading of CIPN [33] (Table 1).
Clinical Effectiveness. Clinical effectiveness was assessed according to what is previously described $[32,34]$.

Complete Remission (CR). The patients felt completely free from all symptoms, with the grading of CIPN reduced to grade 0 .

Partial Remission (PR). Symptoms abated obviously, and the grading of CIPN reduced $\geq 1$ grade.

Nonperceptible (NP). Compared with before treatment symptoms have not abated, and the grading of CIPN did not reduce.

$$
\text { Remission Rate }=\mathrm{CR}+\mathrm{PR} \text {. }
$$

Nerve Conduction Velocity. Changes in values of sensory nerve conduction velocity (SNCV) or motor sensory nerve conduction velocity (MNCV) were measured by validated methods after 1 week of RA treatment or more.

Quality of Life (Qol) and Adverse Events. We extracted Qol, measured as Karnofsky (KPS) scale or Eastern Cooperative Oncology Group (ECOG) scale. Adverse events were also extracted.

2.4. Exclusion Criteria. We excluded studies with unclear diagnostic criteria and without the use of RA. Combinations of herbs and other forms of treatment (e.g., acupuncture or moxibustion) were excluded.

2.5. Data Extraction and Quality Assessment. Data were entered into an electronic database by two authors (Bo Deng and Liqun Jia) independently. Where differences in opinion existed, they were resolved by a third party. Improved Jadad scale was used to assess the quality of RCTs, including randomization, blinding of participants, personnel, and outcome assessors, incomplete outcome data, and other threats to validity [35]. High quality is $4-7$ points. Low quality is $1-3$ points.

2.6. Data Synthesis. Review Manager (RevMan) 5.0 software, provided by the Cochrane Collaboration (UK), was used to analyze the results of the trials. Dichotomous data were expressed as odds ratio (OR). Continuous data were expressed as mean difference (MD). Heterogeneity between results of different trials was tested, and heterogeneity was presented as significant when $I^{2}$ is over $50 \%$ or $P<0.1$. Random effect model was used for the meta-analysis if there was significant heterogeneity and fixed effect model was used when the heterogeneity was not significant [35]. Publication bias was explored via a funnel plot analysis.

\section{Results}

3.1. Description of Studies and Methodological Quality (Figure 1 and Table 2). Our primary searches identified 841 references from the above databases. After duplicates, animal studies, case reports, reviews, and obvious ineligibility were removed, 
TABLE 1: Grading scales used to evaluate oxaliplatin-induced peripheral neuropathy.

\begin{tabular}{lllll}
\hline & Grade 1 & Grade 2 & Grade 3 & Grade 4 \\
\hline Levi et al. [31] & $\begin{array}{l}\text { Paresthesia or insensitive, } \\
\text { complete relief in 1 week }\end{array}$ & $\begin{array}{l}\text { Paresthesia or insensitive, } \\
\text { complete relief in 14 days }\end{array}$ & $\begin{array}{l}\text { Paresthesia or insensitive, } \\
\text { complete relief in 21 days }\end{array}$ & $\begin{array}{l}\text { Paresthesia or insensitive, } \\
\text { combined with functional } \\
\text { abnormality }\end{array}$ \\
\hline Miller et al. [32] & $\begin{array}{l}\text { Paresthesias and/or } \\
\text { decreased tendon reflex }\end{array}$ & $\begin{array}{l}\text { Severe paresthesia and/or } \\
\text { mild anergia }\end{array}$ & $\begin{array}{l}\text { Intolerable paresthesia } \\
\text { and/or marked motor loss }\end{array}$ & Paralysis \\
\hline CTCAE 4.03 [33] & $\begin{array}{l}\text { Asymptomatic; loss of deep } \\
\text { tendon reflexes or } \\
\text { paresthesia }\end{array}$ & $\begin{array}{l}\text { Moderate symptoms; } \\
\text { limiting instrumental ADL }\end{array}$ & $\begin{array}{l}\text { Severe symptoms; limiting } \\
\text { self-care ADL }\end{array}$ & $\begin{array}{l}\text { Life-threatening } \\
\text { consequences; urgent } \\
\text { intervention indicated }\end{array}$ \\
\hline
\end{tabular}

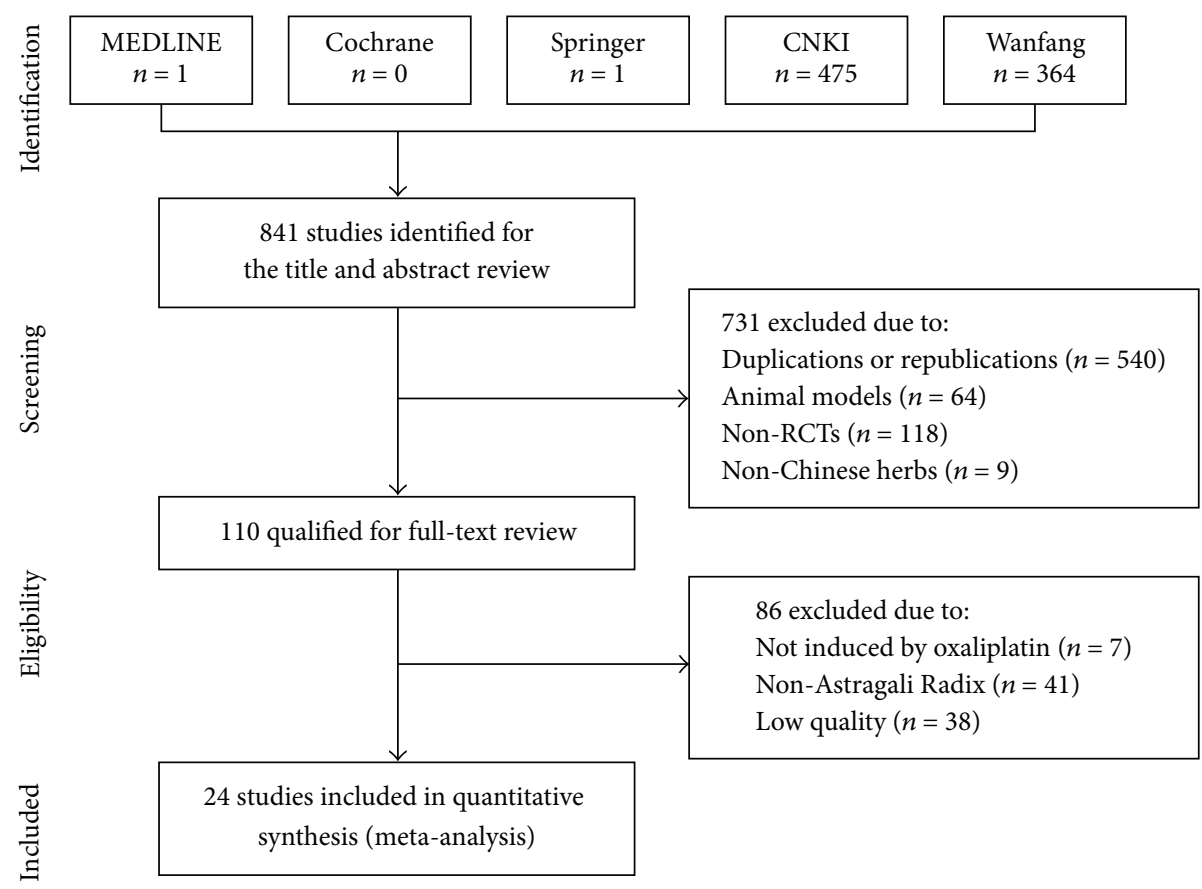

FIGURE 1: Flow chart of included studies in this systematic review.

we retrieved a total of 110 references for further assessment. After full-text reviews, 24 trials were included [5-28]. Included trials were published from 2009 to 2015, with the years 2011 to 2015 having a larger number of trials (20 trials, $85.70 \%$ patients) than other years. All trials were conducted in mainland China. Since all included trials were assessed to be of high quality (improved Jadad score of 4 or 5 points), the risk of bias in this systematic review was low. All 24 trials employed computer software or random number tables for randomization. Nine trials used conventional medicine as control, and only one trial performed double-blinding.

3.2. Participants. In total, 1552 participants with OXAL treatment were included in these 24 trials. The average size of the trials was 66 participants, ranging from 40 to 135 per trial. Eleven trials enrolled only inpatients $(n=689$ patients, $44.39 \%)$. The remaining 13 trials did not specify the setting ( $n=863$ patients, $55.61 \%$ ). All trials included both adult male and female patients, with $58.63 \%$ participants being male.
Types of cancer in participants included colorectal cancer ( $n=1033$ patients), gastric cancer ( $n=399$ patients), and lung cancer/breast cancer/other cancers ( $n=52$ patients). The cancers of 68 patients were not specified. Accumulated OXAL dose varied from $130 \mathrm{mg} / \mathrm{m}^{2}$ to $800 \mathrm{mg} / \mathrm{m}^{2}$, with $260-$ $600 \mathrm{mg} / \mathrm{m}^{2}$ (11 trials) being the most common. Eighteen trials used Levi's grading of CIPN, 3 used CTCAE criteria of CIPN, and 3 used WHO criteria of CIPN.

3.3. Intervention Comparisons (Tables 3 and 4). Sixteen trials ( $n=1060$ patients) compared RA-based intervention with no intervention. Three trials ( $n=159$ patients) tested RAbased prescriptions against mecobalamin. Another 5 trials ( $n=333$ patients) tested RA-based prescriptions in combination treatment remedies compared to the same western medications for CIPN management. Three types of administration methods were employed in these 24 trials, including oral administration (10 trials), topical administration (12 trials), and intravenous drip (1 trial). One trial employed 
TABLE 2: Characteristics of studies included in this systematic review.

\begin{tabular}{|c|c|c|c|c|c|c|c|}
\hline Author & Year & $\begin{array}{l}\text { Sample } \\
\text { size }\end{array}$ & $\begin{array}{l}\text { Mean age (year) } \\
\text { (median/range) }\end{array}$ & $\%$ men & Chemotherapy & $\begin{array}{l}\text { Radix Astragali } \\
\text { intervention }\end{array}$ & Control \\
\hline Cui et al. [5] & 2009 & 40 & 60 & 57.5 & FOLFOX & Single herb extract & No intervention \\
\hline Feng [6] & 2011 & 40 & $28 \sim 55$ & 67.5 & FOLFOX & $\begin{array}{l}\text { Compound } \\
\text { prescription }\end{array}$ & No intervention \\
\hline Huang et al. [7] & 2013 & 61 & 62.3 & 62.3 & FOLFOX & $\begin{array}{l}\text { Compound } \\
\text { prescription }\end{array}$ & No intervention \\
\hline Huang et al. [8] & 2010 & 60 & 46 & 71.7 & FOLFOX & $\begin{array}{l}\text { Compound } \\
\text { prescription }\end{array}$ & No intervention \\
\hline Jin et al. [9] & 2015 & 77 & 47.2 & 48.1 & FOLFOX & $\begin{array}{l}\text { Compound } \\
\text { prescription }\end{array}$ & No intervention \\
\hline Kong [10] & 2012 & 40 & $40 \sim 60$ & 52.5 & OXAL & $\begin{array}{l}\text { Compound } \\
\text { prescription }\end{array}$ & No intervention \\
\hline Li et al. [11] & 2013 & 60 & 50.1 & 31.7 & FOLFOX & $\begin{array}{l}\text { Compound } \\
\text { prescription }\end{array}$ & GSH \\
\hline Liang et al. [12] & 2012 & 84 & $32 \sim 73$ & 70.2 & FOLFOX & $\begin{array}{l}\text { Compound } \\
\text { prescription }\end{array}$ & No intervention \\
\hline Liang et al. [13] & 2015 & 135 & 47.8 & 67.4 & FOLFOX & $\begin{array}{l}\text { Compound } \\
\text { prescription }\end{array}$ & No intervention \\
\hline Lin and Luo [14] & 2011 & 90 & 51 & 54.4 & FOLFOX & $\begin{array}{l}\text { Compound } \\
\text { prescription }\end{array}$ & No intervention \\
\hline Liu et al. [15] & 2011 & 60 & 61.5 & 64.3 & $\begin{array}{l}\text { FOLFOX, } \\
\text { OXAL }\end{array}$ & $\begin{array}{l}\text { Compound } \\
\text { prescription }\end{array}$ & Mecobalamin \\
\hline Liu [16] & 2009 & 68 & $31 \sim 70$ & 60.3 & FOLFOX & $\begin{array}{l}\text { Compound } \\
\text { prescription }\end{array}$ & No intervention \\
\hline Lv [17] & 2015 & 90 & 53.0 & 53.3 & OXAL & $\begin{array}{l}\text { Compound } \\
\text { prescription }\end{array}$ & Mecobalamin \\
\hline Qin and Sun [18] & 2015 & 42 & 55 & 61.9 & FOLFOX & $\begin{array}{l}\text { Compound } \\
\text { prescription }\end{array}$ & Mecobalamin \\
\hline Qin et al. [19] & 2012 & 68 & 57.2 & 47.1 & OXAL, TAX & $\begin{array}{l}\text { Compound } \\
\text { prescription }\end{array}$ & Cobamamide \\
\hline Shen et al. [20] & 2015 & 60 & 59.7 & 65.0 & OXAL & $\begin{array}{l}\text { Compound } \\
\text { prescription }\end{array}$ & Mecobalamin \\
\hline Sun et al. [21] & 2010 & 60 & 55.3 & 63.3 & $\begin{array}{l}\text { FOLFOX, } \\
\text { XELOX, TAX + } \\
\text { 5-Fu }\end{array}$ & $\begin{array}{l}\text { Compound } \\
\text { prescription }\end{array}$ & Mecobalamin \\
\hline Tan and Qi [22] & 2015 & 63 & $31 \sim 70$ & 60.3 & OXAL & $\begin{array}{l}\text { Compound } \\
\text { prescription }\end{array}$ & Mecobalamin \\
\hline Wang [23] & 2015 & 60 & 52.3 & 50.0 & FOLFOX & $\begin{array}{l}\text { Compound } \\
\text { prescription }\end{array}$ & $\begin{array}{l}\mathrm{Ca} / \mathrm{Mg} \\
\text { infusions }\end{array}$ \\
\hline Wu et al. [24] & 2015 & 89 & 49.2 & 70.8 & Platinum, TAX, & $\begin{array}{l}\text { Compound } \\
\text { prescription }\end{array}$ & No intervention \\
\hline Wu et al. [25] & 2012 & 60 & $23 \sim 71$ & 65.8 & FOLFOX & $\begin{array}{l}\text { Compound } \\
\text { prescription }\end{array}$ & No intervention \\
\hline Wu et al. [26] & 2015 & 60 & 59.7 & 65.6 & $\begin{array}{c}\text { Platinum, TAX, } \\
\text { VCR }\end{array}$ & $\begin{array}{l}\text { Compound } \\
\text { prescription }\end{array}$ & No intervention \\
\hline Xu et al. [27] & 2011 & 40 & $*$ & 45.0 & OXAL & $\begin{array}{l}\text { Compound } \\
\text { prescription }\end{array}$ & No intervention \\
\hline Zhang and Lu [28] & 2013 & 70 & $31-77$ & 65.7 & FOLFOX & $\begin{array}{c}\text { Single herb extract } \\
+ \\
\text { thioctic acid }\end{array}$ & No intervention \\
\hline
\end{tabular}

FOLFOX: oxaliplatin + 5-fluorouracil + calcium folinate.

5-Fu: 5-fluorouracil.

GSH: glutathione.

$O X A L$ : oxaliplatin.

TAX: taxol.

VCR: vincristine.

XELOX: oxaliplatin + capecitabine. 


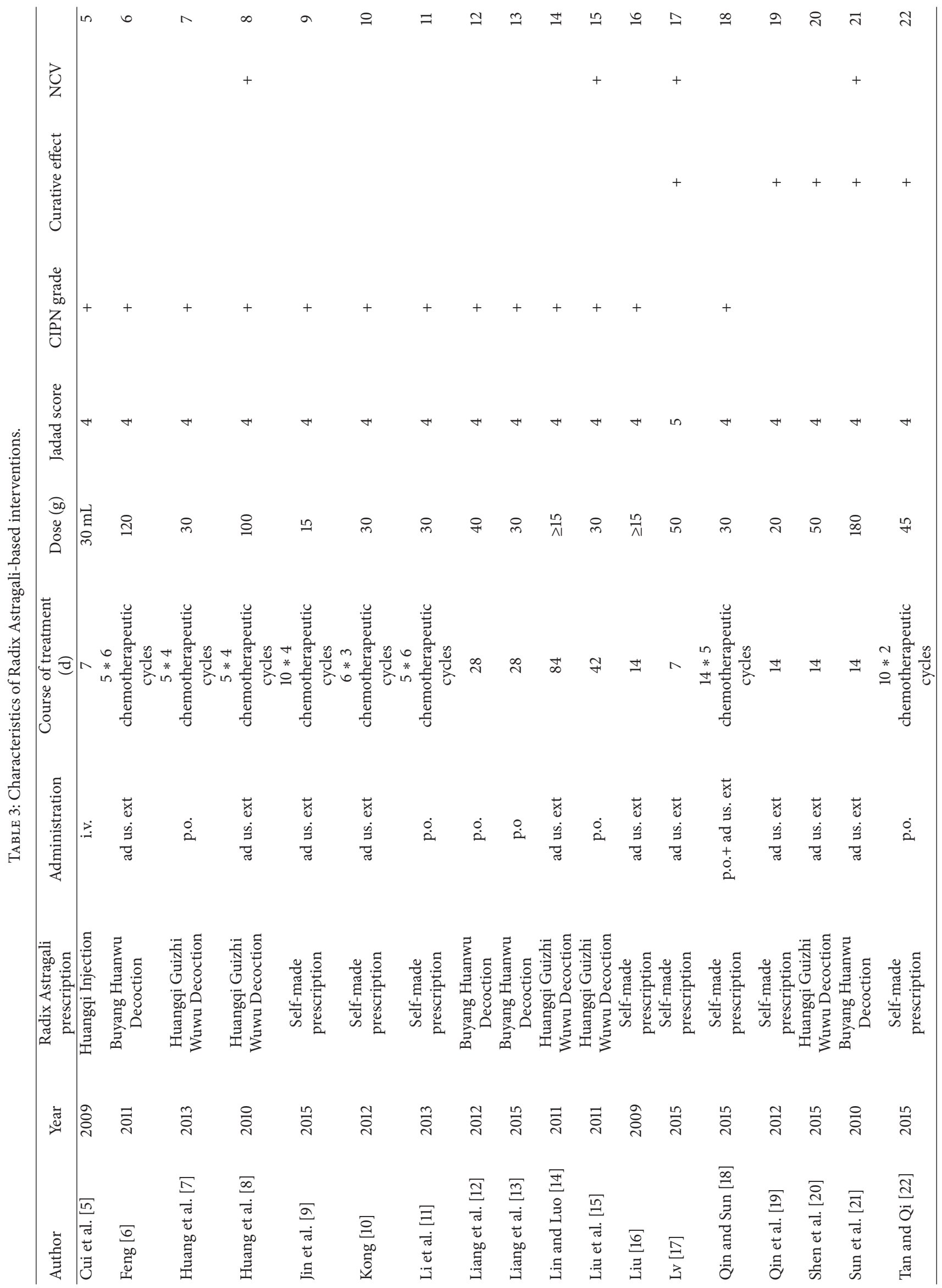







TABLE 4: Chinese herbs combination in Radix Astragali-based prescriptions.

\begin{tabular}{|c|c|c|c|c|}
\hline Latin name & English name & Chinese name & Counts & Frequency $(\%)$ \\
\hline Angelica sinensis (Oliv.) Diels & Radix Angelicae sinensis & Danggui & 19 & 86.36 \\
\hline Cinnamomum cassia Presl & Ramulus Cinnamomi & Guizhi & 17 & 77.27 \\
\hline Paeonia lactiflora Pall. & Radix Paeoniae Alba & Baishao & 16 & 72.73 \\
\hline Spatholobus suberectus Dunn & Caulis spatholobi & Jixueteng & 13 & 59.09 \\
\hline Ligusticum chuanxiong Hort. & Rhizoma Chuanxiong & Chuanxiong & 12 & 54.55 \\
\hline Carthamus tinctorius L. & Flos Carthami & Honghua & 10 & 50.00 \\
\hline Prunus persica (L.) Batsch & Semen persicae & Taoren & 9 & 40.91 \\
\hline Ziziphus jujuba Mill. & Fructus Jujubae & Dazao & 8 & 36.36 \\
\hline Salvia miltiorrhiza Bge. & Radix Salviae Miltiorrhizae & Danshen & 7 & 31.82 \\
\hline Zingiber officinale Rosc. & Rhizoma Zingiberis (recens) & Jiang & 7 & 31.82 \\
\hline Pheretima aspergillum (E. Perrier) & Pheretima & Dilong & 7 & 31.82 \\
\hline
\end{tabular}

oral administration combined with topical administration. The most popular prescriptions were modified Huangqi Guizhi Wuwu Decoction (7 trials) and modified Buyang Huanwu Decoction (5 trials). Prescriptions composed by the investigators themselves were combined and modified from these 2 prescriptions (10 trials). More than $50 \%$ of RA-based prescriptions included Danggui, Guizhi, Baishao, Jixueteng, Chuanxiong, and Honghua. These herbs may augment the effects of RA intervention on CIPN. Doses of RA ranged from $15 \mathrm{~g}$ to $180 \mathrm{~g}$ but most fell in the range of 30 to $50 \mathrm{~g}$ (12 trials). The duration of treatment varied mostly from 2 weeks to 8 chemotherapy cycles. Regarding topical administration, the temperature of decoction ranged from $35^{\circ} \mathrm{C}$ to $42^{\circ} \mathrm{C}$, but most were in the range of $38-42^{\circ} \mathrm{C}$ ( 6 trials).

\subsection{Effects of Interventions}

3.4.1. Incidence of All-Grade CIPN (Figure 2). Eighteen trials reported incidence of all-grade (grades 1-4) CIPN. Five trials included CIPN patients and reported curative effects of RA-based prescriptions. And 1 trial only reported incidence of high-grade CIPN. Fifteen trials compared RAbased intervention to no intervention. RA-based intervention significantly reduced CIPN occurrence $(n=993$ patients; OR, $0.19,95 \% \mathrm{CI}, 0.14$ to $0.25, P<0.01)$. One trial compared RA-based prescription to mecobalamin. RA-based prescription significantly reduced CIPN occurrence $(n=42$ patients; OR, $0.17,95 \%$ CI, 0.03 to $0.94, P<0.05$ ). Two trials compared RA-based prescriptions plus reduced glutathione or $\mathrm{Ca} / \mathrm{Mg}$ infusions with the same conventional medications. RA-based prescriptions in combined remedies significantly reduced CIPN occurrence ( $n=120$ patients; OR, $0.42,95 \%$ CI, 0.18 to $0.97, P<0.05)$.

3.4.2. Incidence of High-Grade CIPN (Figure 3). Nineteen trials reported incidence of high-grade (grades 3-4) CIPN. No patients develop high-grade CIPN in 1 trial. Therefore 18 trials were included in a forest plot. Fourteen trials compared RA-based intervention to no intervention, mostly by using Levi's grading (11 trials). RA-based intervention significantly reduced high-grade CIPN ( $n=931$ patients; OR, $0.17,95 \%$ CI, 0.09 to $0.31, P<0.01)$. However, 2 trials compared modified RA-based prescriptions to mecobalamin, and 2 trials compared RA-based prescriptions plus reduced glutathione or $\mathrm{Ca} / \mathrm{Mg}$ infusions with the same conventional medications. In these trials, there was no statistical difference between groups.

3.4.3. Curative Effect of RA-Based Prescriptions (Figure 4). Five trials included 341 patients that had already developed CIPN and reported curative effects of RA-based prescriptions. The total effective rate of RA-based prescriptions was $79.07 \%$, compared with $54.44 \%$ in the control group. Three trials compared curative effects of RA-based prescriptions plus mecobalamin to mecobalamin alone, where RA-based prescriptions were significantly more effective in relieving CIPN ( $n=213$ patients; OR, 4.84, 95\% CI, 2.38 to 9.83, $P<$ $0.01)$. However, 1 trial compared RA-based prescription to mecobalamin, and 1 trial compared RA-based prescription to no treatment. In these trials, there was no statistical difference between groups.

3.4.4. SNCV and MNCV (Figures 5 and 6). Six trials reported RA-based interventions significantly improved SNCV (MD $4.42 \mathrm{~m} / \mathrm{s}, 95 \%$ CI 3.27 to $5.57, P<0.01)$. However, regarding $\mathrm{MNCV}$, there was no statistical difference between groups.

3.4.5. Safety, Quality of Life, and Publication Bias. Among the 24 articles incorporated in the meta-analysis, no adverse events associated with RA-based interventions were reported. Nineteen trials reported Qol (KPS score > 60 or ECOG score $\leq 2$ ) before RA intervention, and 2 trials reported Qol improvement. One trial reported the percentage of patients with Qol improvement while the other reported the increased level of KPS score. Therefore, the results of these 2 trials could not be combined in the meta-analysis. Exploration of the funnel plots (Figure 7) for all-grade CIPN, high-grade CIPN, and curative effects between RA-based interventions and control suggested near symmetry. No significant publication bias was found. 


\begin{tabular}{|c|c|c|c|c|c|c|c|c|c|c|}
\hline \multirow{3}{*}{$\begin{array}{l}\text { Study or subgroup } \\
\text { 1.1.1 RA versus no intervention }\end{array}$} & \multicolumn{2}{|c|}{ Experimental } & \multicolumn{2}{|c|}{ Control } & & \multirow{2}{*}{$\begin{array}{c}\text { Odds ratio } \\
\text { M-H, fixed, } 95 \% \text { CI } \\
\end{array}$} & \multirow{2}{*}{\multicolumn{4}{|c|}{$\begin{array}{c}\text { Odds ratio } \\
\text { M-H, fixed, 95\% CI }\end{array}$}} \\
\hline & \multirow[t]{2}{*}{ Events } & \multirow[t]{2}{*}{ Total } & \multirow[t]{2}{*}{ Events } & \multirow[t]{2}{*}{ Total } & & & & & & \\
\hline & & & & & Weight & M-H, fixed, 95\% CI & & & & \\
\hline Cui et al. 2009 & 6 & 20 & 18 & 20 & $5.2 \%$ & $0.05[0.01,0.27]$ & & & & \\
\hline Feng 2011 & 7 & 20 & 15 & 20 & $4.0 \%$ & $0.18[0.05,0.70]$ & & & & \\
\hline Huang et al. 2013 & 15 & 30 & 27 & 31 & $5.5 \%$ & $0.15[0.04,0.53]$ & & $\longrightarrow$ & & \\
\hline Huang et al. 2010 & 8 & 30 & 25 & 30 & $7.6 \%$ & $0.07[0.02,0.26]$ & & 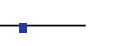 & & \\
\hline Jin et al. 2015 & 29 & 39 & 36 & 38 & $3.9 \%$ & $0.16[0.03,0.79]$ & & & & \\
\hline Kong 2012 & 5 & 20 & 12 & 20 & $3.7 \%$ & $0.22[0.06,0.86]$ & & & & \\
\hline Liang et al. 2012 & 18 & 46 & 30 & 38 & $8.2 \%$ & $0.17[0.06,0.46]$ & & & & \\
\hline Liang et al. 2015 & 30 & 74 & 48 & 61 & $12.9 \%$ & $0.18[0.09,0.40]$ & & & & \\
\hline Lin and Luo 2011 & 19 & 45 & 36 & 45 & $8.6 \%$ & $0.18[0.07,0.47]$ & & & & \\
\hline Liu 2009 & 17 & 34 & 28 & 34 & $5.8 \%$ & $0.21[0.07,0.65]$ & & & & \\
\hline Wu et al. 2015 & 25 & 45 & 35 & 45 & $6.4 \%$ & $0.36[0.14,0.89]$ & & & & \\
\hline Wu et al. 2012 & 13 & 19 & 16 & 19 & $2.1 \%$ & $0.41[0.08,1.95]$ & & & - & \\
\hline Wu et al. 2015 & 7 & 30 & 20 & 30 & $6.3 \%$ & $0.15[0.05,0.47]$ & & & & \\
\hline Xu et al. 2011 & 5 & 20 & 12 & 20 & $3.7 \%$ & $0.22[0.06,0.86]$ & & & & \\
\hline Zhang and $\mathrm{Lu} 2013$ & 10 & 35 & 21 & 35 & $6.2 \%$ & $0.27[0.10,0.72]$ & & & & \\
\hline Subtotal (95\% CI) & & 507 & & 486 & $89.9 \%$ & $0.19[0.14,0.25]$ & & & & \\
\hline Total events & 214 & & 379 & & & & & & & \\
\hline Heterogeneity: $\chi^{2}=8$ & $P=0.87$ & $; I^{2}=($ & & & & & & & & \\
\hline Test for overall effect: $Z$ & $<0.000$ & & & & & & & & & \\
\hline 1.1.2 RA versus mecoba & & & & & & & & & & \\
\hline Qin and Sun 2015 & 13 & 21 & 19 & 21 & $3.0 \%$ & $0.17[0.03,0.94]$ & & & & \\
\hline Subtotal (95\% CI) & & 21 & & 21 & $3.0 \%$ & $0.17[0.03,0.94]$ & & & & \\
\hline Total events & 13 & & 19 & & & & & & & \\
\hline Heterogeneity: not appl & & & & & & & & & & \\
\hline Test for overall effect: $Z$ & $=0.04)$ & & & & & & & & & \\
\hline $\begin{array}{l}\text { 1.1.3 RA in combined re } \\
\text { versus the same western }\end{array}$ & & & & & & & & & & \\
\hline Li et al. 2013 & 5 & 30 & 11 & 30 & $3.8 \%$ & $0.35[0.10,1.16]$ & & & & \\
\hline Wang 2015 & 20 & 30 & 24 & 30 & $3.3 \%$ & $0.50[0.15,1.62]$ & & & - & \\
\hline Subtotal (95\% CI) & & 60 & & 60 & $7.1 \%$ & $0.42[0.18,0.97]$ & & & & \\
\hline Total events & 25 & & 35 & & & & & & & \\
\hline Heterogeneity: $\chi^{2}=0$ & $=0.67)$ & $I^{2}=0 \%$ & & & & & & & & \\
\hline Test for overall effect: 2 & $=0.04)$ & & & & & & & & & \\
\hline Total (95\% CI) & & 588 & & 567 & $100.0 \%$ & $0.20[0.16,0.27]$ & & $\gamma$ & & \\
\hline Total events & 252 & & 433 & & & & & & & \\
\hline Heterogeneity: $\chi^{2}=11$ & $(P=0.8$ & 2); $I^{2}=$ & & & & & & & $1 \quad 10$ & 100 \\
\hline Test for overall effect: 2 & $P<0.000$ & & & & & & $\begin{array}{c}0.01 \\
\text { Favours }\end{array}$ & $\begin{array}{l}0.1 \\
\text { erimental }\end{array}$ & $\begin{array}{lr}1 & 10 \\
& \text { Favours c }\end{array}$ & \\
\hline
\end{tabular}

FIGURE 2: Forest plot of comparison: incidence of all-grade oxaliplatin-induced peripheral neuropathy.

\section{Discussion}

CIPN is not recorded in classic TCM books, so it remains a big challenge for TCM oncologists. Based on syndrome differentiation and treatment, TCM oncologists believe that CIPN falls under the category of Bi syndrome in TCM. The pathogenesis of CIPN is believed to be asthenia of qi and blood, qi stagnation and blood stasis. These lead to tendon and vessel malnutrition and stasis in collaterals. The treatment includes benefiting qi and nourishing blood, regulating ying and wei, and promoting blood circulation to remove meridian obstruction.

RA is one of the most commonly used herbs tonifying qi. In vitro and in vivo studies suggest RA extract can be a potential nerve growth-promoting factor, being salutary in encouraging the growth of axons in peripheral nerves [36]. 


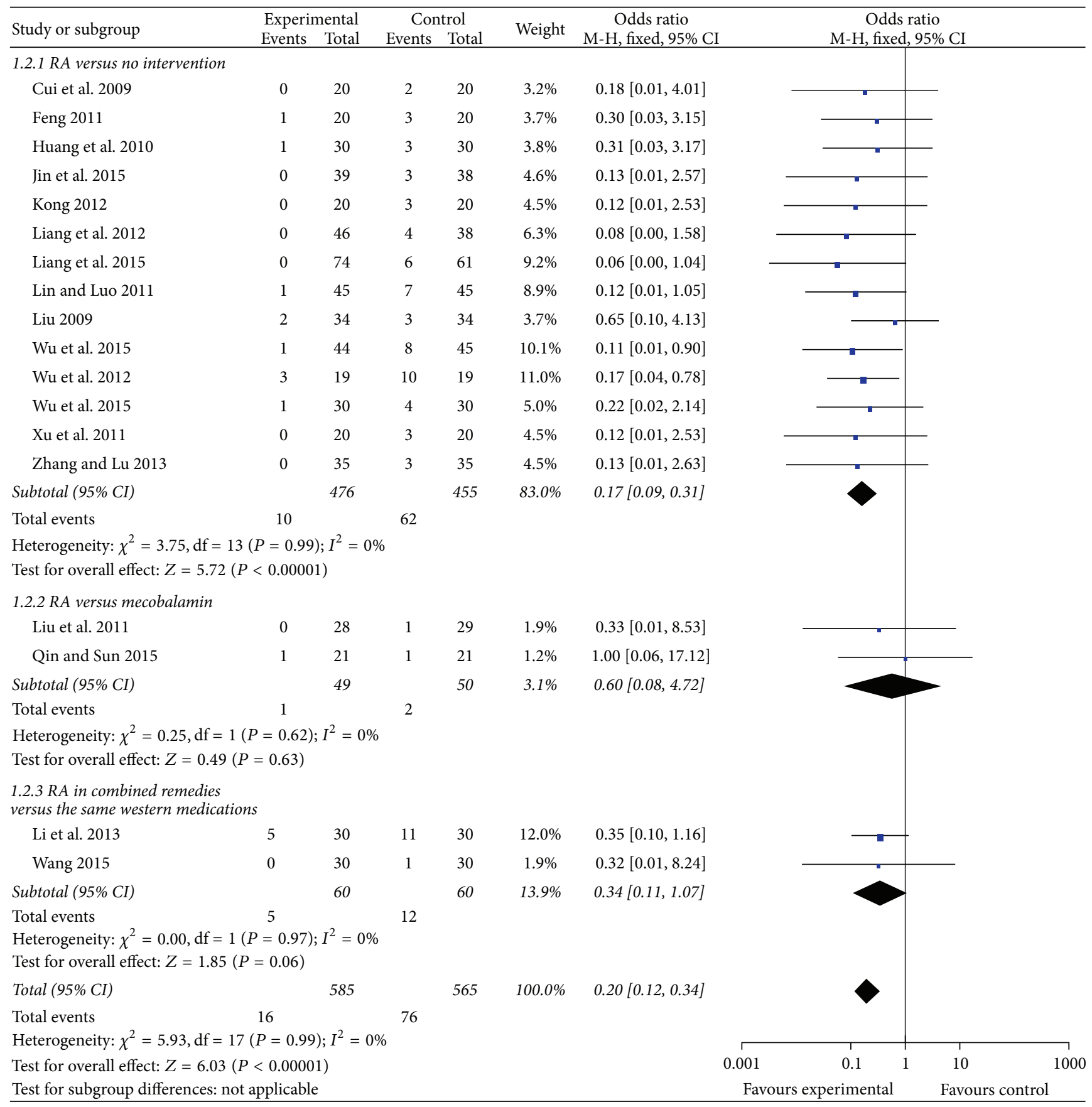

FIGURE 3: Forest plot of comparison: incidence of high-grade oxaliplatin-induced peripheral neuropathy.

Astragaloside IV, an active ingredient in RA, contributed to sciatic nerve regeneration and functional recovery in mice. The mechanism underlying this effect may be associated with the upregulation of growth-associated protein-43 expression [37]. RA extract promoted neural-directed differentiation of mesenchymal stem cells into nerve cells in vitro and also had neuroprotective effects on the central nervous system $[38,39]$.

This review identified a relatively large amount of evidence on the effectiveness of RA-based interventions, either tested alone or tested in combined remedies, for the prevention and treatment of OXAL induced peripheral neuropathy. Compared with no intervention or conventional western medicine, RA-based interventions have the potential of being more effective in relieving CIPN. RA-based interventions also lead to improvement of SNCV. No adverse event was reported and 2 trials reported Qol improvement after RAbased interventions. In China, there is a general perception that it could improve Qol for various conditions. However, 


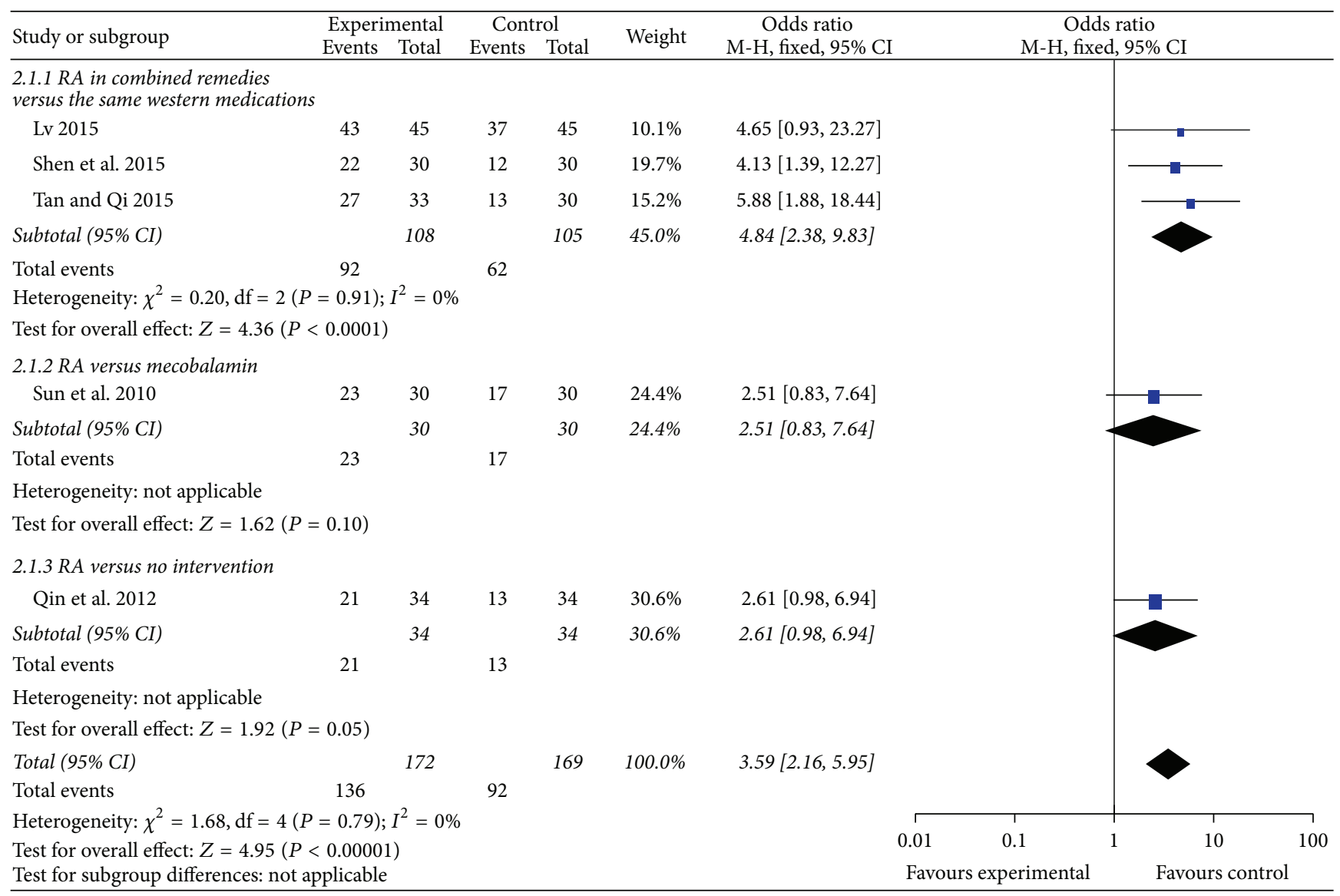

FIGURE 4: Forest plot of comparison: curative effects of Radix Astragali-based prescriptions on oxaliplatin-induced peripheral neuropathy.

clinical trials need to monitor and report Qol improvement.

Most of RA-based prescriptions included Danggui, Guizhi, Baishao, Jixueteng, Chuanxiong, and Honghua. These herbs may improve the effects of RA intervention on CIPN. Individualized treatment in TCM requires the modification of herbs with various symptoms in different patients. So the herbs included in RA-based prescriptions were heterogeneous. There were variations in the formulation, dosage, administration, and duration of treatment in the included trials. Even for herbal intervention of the same name, there were still differences in the specific composition or dose of included Chinese herbal medicine. Information about quality control was lacking on the development of the herbal preparations or the manufacture of herbal products. Future trials should provide information about standardization, including composition, quality control, and detailed regimens. The majority of trials compared RA-based intervention with no intervention; others used western conventional medicine as controls. Only 1 trial used a formal placebo control, so the positive effect should be interpreted conservatively.

This review has its limitations. We only included studies published in journals. Dissertations and conference papers were not included. Only high quality (improved Jadad score $\geq 4$ points) trials were included. We excluded 38 trials with low quality or insufficient information for assessing risk of bias. Therefore, it may not be possible to achieve a complete summary of all existent evidence. Quantitative subgroup analysis exploring the effects of age, disease history, and duration could not be performed due to insufficient data. No multicenter, large-scale RCTs were identified. Most trials focused on short-term rather than long-term outcomes. Future trials should assure adequate concealment of allocation and blinding of outcome assessors.

\section{Conclusions}

From our study, we found that RA-based intervention may have clinical effectiveness for relieving OXAL induced peripheral neuropathy and lead to improvement of SNCV. However, the evidence is not sufficient. In the future, results from double-blind, multicenter, large-scale RCTs are needed to draw more definitive conclusions.

\section{Competing Interests}

The authors declare that there are no competing interests regarding the publication of this manuscript. 


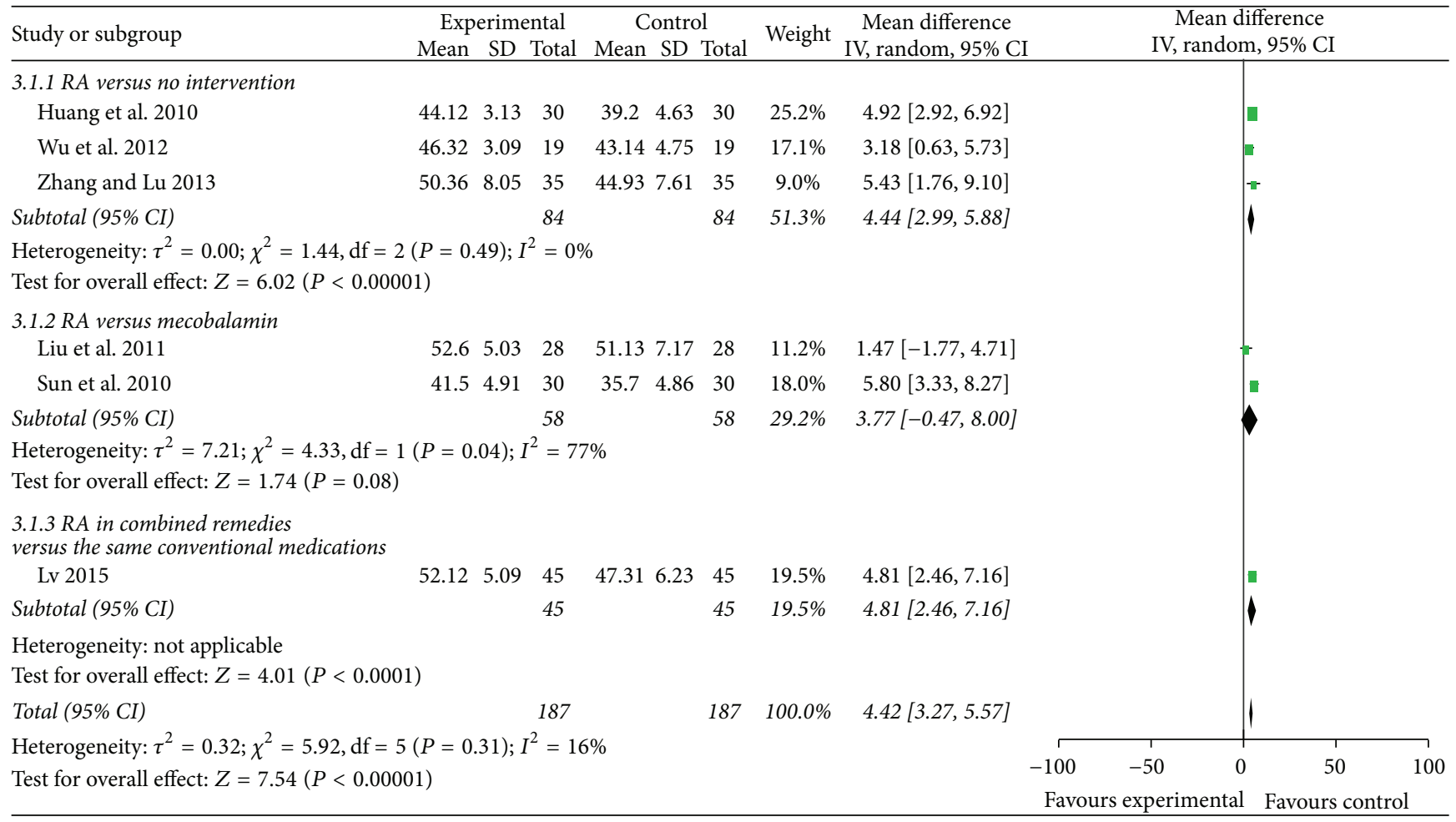

FIGURE 5: Forest plot of comparison: sensory nerve conduction velocity.

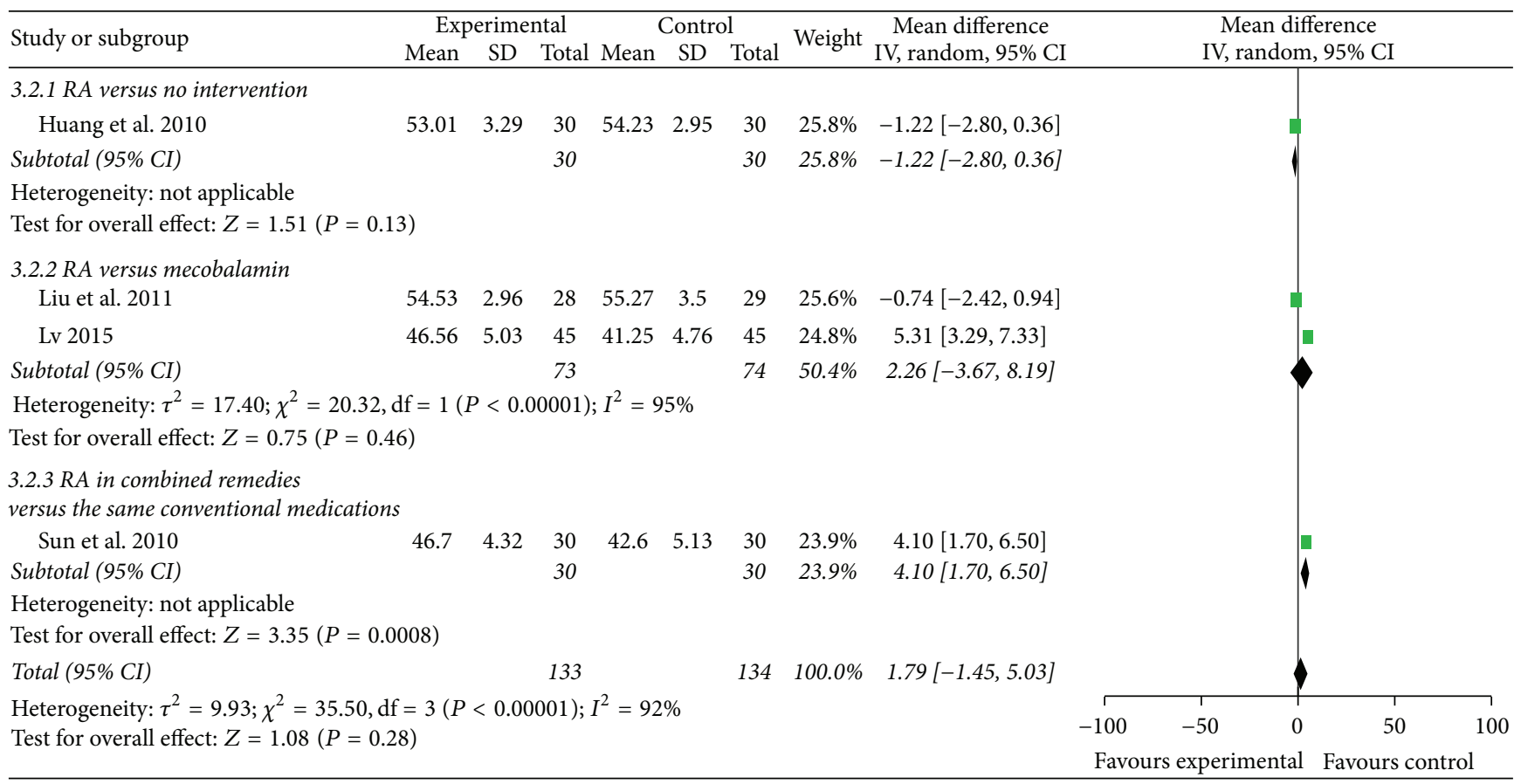

FIGURE 6: Forest plot of comparison: motor nerve conduction velocity. 


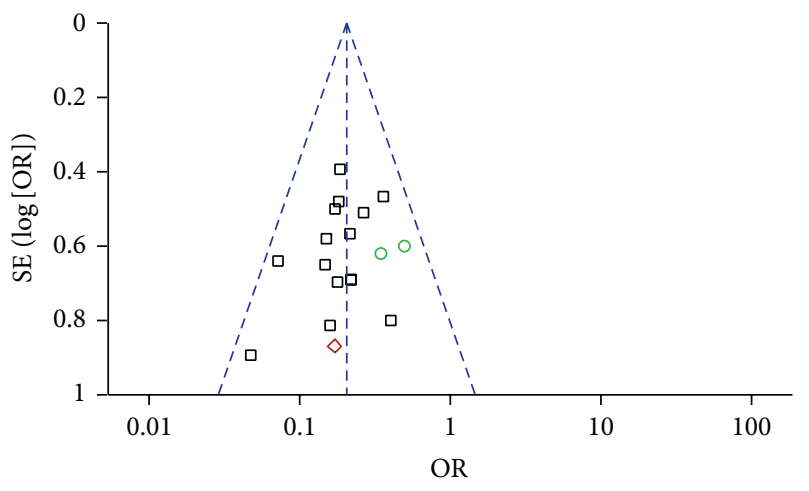

Subgroups

$\square$ RA versus no intervention

$\diamond \mathrm{RA}$ versus mecobalamin

- RA in combined remedies versus the same western medications

(a)

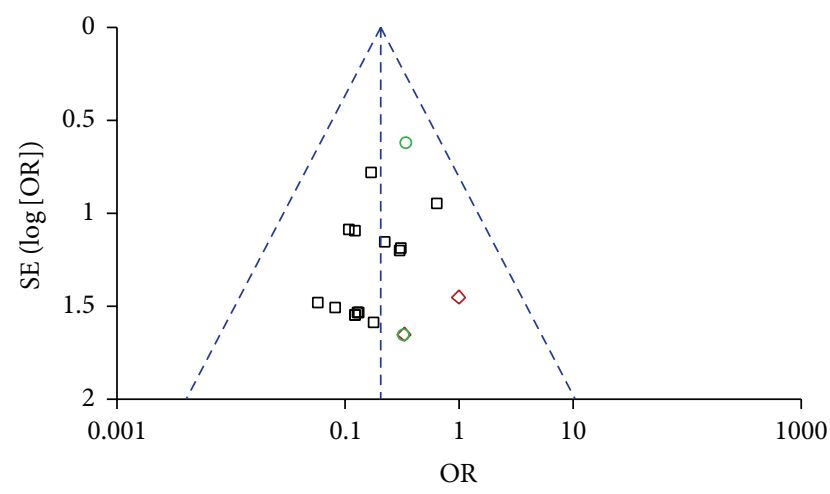

Subgroups

$\square$ RA versus no intervention

$\diamond$ RA versus mecobalamin

RA in combined remedies versus the same western medications

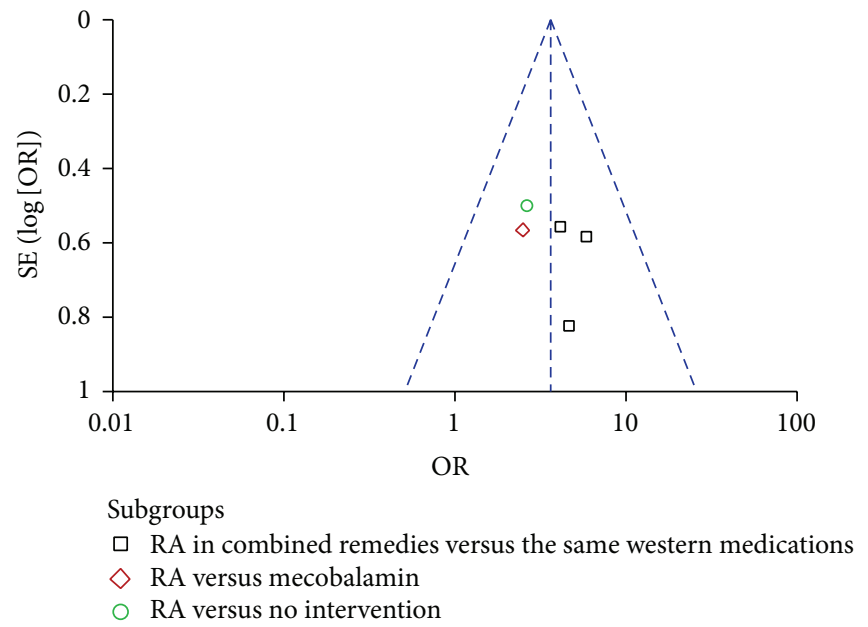

(c)

Figure 7: Funnel plot analysis of risk of bias. (a) Funnel plot analysis of incidence of all-grade chemotherapy-induced peripheral neuropathy (CIPN). (b) Funnel plot analysis of incidence high-grade CIPN (grades 3-4). (c) Funnel plot analysis of curative effects of Radix Astragalibased prescriptions on CIPN.

\section{Acknowledgments}

This work was supported by Beijing Municipal Science \& Technology Commission no. Z151100003815019 and National Fund of Natural Sciences no. 81173421 of China. The authors thank Dr. Wei Sun for translating Latin names of herbal medicine.

\section{References}

[1] R. H. Wilson, T. Lehky, R. R. Thomas, M. G. Quinn, M. K. Floeter, and J. L. Grem, "Acute oxaliplatin-induced peripheral nerve hyperexcitability," Journal of Clinical Oncology, vol. 20, no. 7, pp. 1767-1774, 2002.

[2] H. Kelly and R. M. Goldberg, "Systemic therapy for metastatic colorectal cancer: current options, current evidence," Journal of Clinical Oncology, vol. 23, no. 20, pp. 4553-4560, 2005.

[3] T. André, C. Boni, L. Mounedji-Boudiaf et al., "Oxaliplatin, fluorouracil, and leucovorin as adjuvant treatment for colon cancer," The New England Journal of Medicine, vol. 350, no. 23, pp. 2343-2351, 2004.

[4] L. Ventzel, A. B. Jensen, A. R. Jensen, T. S. Jensen, and N. B. Finnerup, "Chemotherapy-induced pain and neuropathy: a prospective study in patients treated with adjuvant oxaliplatin or docetaxel," Pain, vol. 157, no. 3, pp. 560-568, 2016.

[5] H. Cui, O. Li, H. Tan, and Y. Li, "Clinical observation of efficacy of Huangqi injection in prevention and treatment of neurotoxicity induced by oxaliplatin-containing chemotherapy regimen," Adverse Drug Reactions Journal, vol. 11, no. 4, pp. 249$252,2009$.

[6] Y. Feng, "Nursing observation of prevention and treatment of oxaliplatin-induced peripheral neuropathy," Strait Pharmaceutical Journal, vol. 23, no. 12, pp. 203-204, 2011.

[7] J. Huang, Q. Lin, Z. Qiu et al., "Clinical study of protective effect of Yiqi Wenjing Yangxue Huoxue recipe combined with reduced glutathione on oxaliplatin-induced chronic neurotoxicity," Chinese Journal of Experimental Traditional Medical Formulae, vol. 19, no. 4, pp. 312-315, 2013. 
[8] Z. Huang, Z. Huang, G. Chen et al., "Clinical study on external bath of 'Huangqi Guizhi Decoction' in relieving oxaliplatininduced peripheral neurotoxicity," Shanghai Journal of Traditional Chinese Medicine, vol. 44, no. 5, pp. 40-42, 2010.

[9] Y. Jin, Q. Su, X. Chen, D. Pang, and G. He, "Effects of TCM fumigation combined with twelve meridians flapping exercises on oxaliplatin-induced peripheral neurotoxicity," Chinese Journal of Modern Nursing, vol. 21, no. 11, pp. 1316-1318, 2015.

[10] M. Kong, "Administration of Huoxue Huayu Herbs in treating patients with oxaliplatin-induced peripheral neurotoxicity," Journal of Qilu Nursing, vol. 18, no. 34, p. 141, 2012.

[11] Z. Li, A. Dai, H. Yang, S. Li, Y. Wan, and W. Yang, "The random parallel control study of protective effect of Rongjin Fang on oxaliplatin-induced chronic neurotoxicity in treating colorectal cancer," Journal of Practical Traditional Chinese Internal Medicine, vol. 27, no. 10, pp. 46-49, 2013.

[12] X. Liang, M. Chen, D. Chen, and Q. Lin, "Liqi Yufeng Decoction relieve oxaliplatin-induced chronic neurotoxicity: a report of 46 cases," Chinese Journal of Traditional Medical Science and Technology, vol. 19, no. 1, p. 94, 2012.

[13] X. Liang, M. Chen, and Q. Lin, "Lixue Yufeng Tang relieve oxaliplatin-induced chronic neurotoxicity in patients of postoperational colorectal cancer: a report of 74 cases," Zhejiang Journal of Traditional Chinese Medicine, vol. 50, no. 7, pp. 522523, 2015.

[14] H. Lin and K. Luo, "Nursing observation of modified Huangqi Guizhi Wuwu Tang in treating peripheral neurotoxicity induced by oxaliplatin," Chinese General Nursing, vol. 9, no. 2, pp. 484485, 2011.

[15] H. Liu, Z. Zhou, L. Wu et al., "Clinical research on the effects of 'Huangqi Guizhi Wuwu Decoction' on peripheral neurotoxicity induced by oxaliplatin," Shanghai Journal of Traditional Chinese Medicine, vol. 45, no. 3, pp. 44-47, 2011.

[16] S. Liu, "Nursing observation of Huoxue Tongluo Formula preventing oxaliplatin-induced peripheral neurotoxicity," Beijing Journal of Traditional Chinese Medicine, vol. 28, no. 1, pp. 4546, 2009.

[17] P. Lv, "Clinical observation of integrated Chinese and Western medicine in the treatment of peripheral neuropathy caused by oxaliplatin," China Medical Herald, vol. 12, no. 21, pp. 131-134, 2015.

[18] B. Qin and C. Sun, "Protective effect of Yiqi Huoxue Formula on oxaliplatin-induced neurotoxicity in colorectal cancer," Shandong Journal of Traditional Chinese Medicine, vol. 34, no. 3, pp. 176-178, 2015.

[19] Y. Qin, H. Lin, and B. Hua, "Clinical observation of network vessel-freeing formula as topical wash combined for 34 cases of chemotherapy-induced peripheral neuropathy," Journal of Traditional Chinese Medicine, vol. 53, no. 23, pp. 2014-2016, 2012.

[20] J. Shen, S. He, X. Sun, N. Hu, and Y. Cai, "Clinical study on external bath of modified Huangqi Guizhi Wuwu Decoction for peripheral neurotoxicity induced by oxaliplatin," Chinese Journal of Information on TCM, vol. 22, no. 11, pp. 13-15, 2015.

[21] W. Sun, X. Li, X. Zhang, Y. Liu, Y. Li, and J. Li, "Buyang Huanwu Tang immersion for treating 34 cases of chemotherapy-induced peripheral neuropathy," Journal of Fujian University of TCM, vol. 20, no. 5, pp. 8-9, 2010.

[22] Z. Tan and Y. Qi, "Clinical study on gastric cancer patients with chemotherapy-induced neurotoxicity treated with Yiqi Wenyang Huoxue Method," Shandong Journal of Traditional Chinese Medicine, vol. 34, no. 2, pp. 101-103, 2015.
[23] Q. Wang, "Huangqi Guizhi Wuwu Tang hand-foot bath combined with $\mathrm{Ca} / \mathrm{Mg}$ infusions in relieving oxaliplatin-induced peripheral neurotoxicity: a clinical observsion," Modern Journal of Integrated Traditional Chinese and Western Medicine, vol. 24, no. 3, pp. 318-320, 2015.

[24] G. Wu, X. Yao, X. Wu, and F. Liu, "Curative effect observsion of modified Huangqi Guizhi Wuwu Tang in relieving postoperative chemotherapy induced peripheral neurotoxicity," Journal of Sichuan of Traditional Chinese Medicine, vol. 33, no. 12, pp. 132-133, 2015.

[25] M. Wu, X. Chen, Y. Zhou, X. Ying, and Y. Wang, "Clinic research of Yiqihuoxue and Jianpibushen therapy on prevention of oxaliplatin-induced neurotoxicity," Chinese Archives of Traditional Chinese Medicine, vol. 30, no. 1, pp. 111-113, 2012.

[26] T. Wu, Y. Jin, Y. Zhong et al., "Efficacy of Huangqi Guizhi Wuwu decoction combined with needle warming moxibustion on peripheral neurotoxicity and immunologic function of patients with malignant cancer after chemotherapy," Shandong Medical Journal, vol. 55, no. 33, pp. 1-4, 2015.

[27] M. Xu, X. Wu, N. Fang, W. Zhu, and S. Zhu, "Clinical observation of external administion of Huoxue Huayu Formula in reliving oxaliplatin-induced peripheral neurotoxicity," Guiding Journal of Traditional Chinese Medicine and Pharmacy, vol. 17, no. 12, pp. 32-33, 2011.

[28] Y. Zhang and X. Lu, "Clinical study of the protective effect of thioctic acid combined with Huangqi Oral Liquid on oxaliplatin-induced neurotoxicity," China Journal of Chinese Medicine, vol. 28, no. 186, pp. 1617-1618, 2013.

[29] Y. Ma, R. Zhou, W. Ye, and H. Liu, "Influence of 'Huangqi Guizhi Wuwu Decoction' on nerve conduction velocity in oxaliplatininduced peripheral neurotoxicity rats," Shanghai Journal of Traditional Chinese Medicine, vol. 45, no. 1, pp. 75-78, 2011.

[30] J. Huo, Y. Hu, J. Yang et al., "Effect of Huangqi Guizhi Wuwu Decoction on chemotherapy-induced peripheral never injury in rats," Journal of Traditional Chinese Medicine, vol. 53, no. 23, pp. 2013-2034, 2012.

[31] F. Levi, J.-L. Misset, S. Brienza et al., "A chronopharmacologic phase II clinical trial with 5-fluorouracil, folinic acid, and oxaliplatin using an ambulatory multichannel programmable pump. High antitumor effectiveness against metastatic colorectal cancer," Cancer, vol. 69, no. 4, pp. 893-900, 1992.

[32] A. B. Miller, B. Hoogstraten, M. Staquet, and A. Winkler, "Reporting results of cancer treatment," Cancer, vol. 47, no. 1, pp. 207-214, 1981.

[33] Cancer Therapy Evaluation Program, Common Terminology Criteria for Adverse Events, Version 4.03, National Cancer Institute, 2010, http://evs.nci.nih.gov/ftp1/CTCAE/CTCAE 4.03_2010-06-14_QuickReference_5x7.pdf.

[34] Y. Shi and Y. Sun, Manual of Clinical Oncology, People's Medical Publishing House, Shelton, Conn, USA, 6th edition, 2015.

[35] J. P. T. Higgins and S. Green, Cochrane Handbook for Systematic Reviews of Interventions Version 5.1.0, The Cochrane Collaboration, 2012, http://handbook.cochrane.org.

[36] M.-C. Lu, C.-H. Yao, S.-H. Wang, Y.-L. Lai, C.-C. Tsai, and Y.-S. Chen, "Effect of Astragalus membranaceus in rats on peripheral nerve regeneration: in vitro and in vivo studies," Journal of Trauma and Acute Care Surgery, vol. 68, no. 2, pp. 434-440, 2010.

[37] X. Zhang and J. Chen, "The mechanism of astragaloside IV promoting sciatic nerve regeneration," Neural Regeneration Research, vol. 8, no. 24, pp. 2256-2265, 2013. 
[38] Y.-C. Si, Q. Li, C.-E. Xie, X. Niu, X.-H. Xia, and C.-Y. $\mathrm{Yu}$, "Chinese herbs and their active ingredients for activating xue (blood) promote the proliferation and differentiation of neural stem cells and mesenchymal stem cells," Chinese Medicine, vol. 9, no. 1, article 13, 2014.

[39] X.-P. Huang, H. Ding, J.-D. Lu, Y.-H. Tang, B.-X. Deng, and C.Q. Deng, "Effects of the combination of the main active components of Astragalus and Panax notoginseng on inflammation and apoptosis of nerve cell after cerebral ischemia-reperfusion," American Journal of Chinese Medicine, vol. 43, no. 7, pp. 14191438, 2015. 


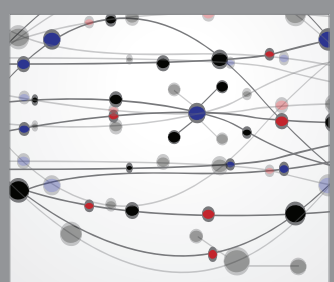

The Scientific World Journal
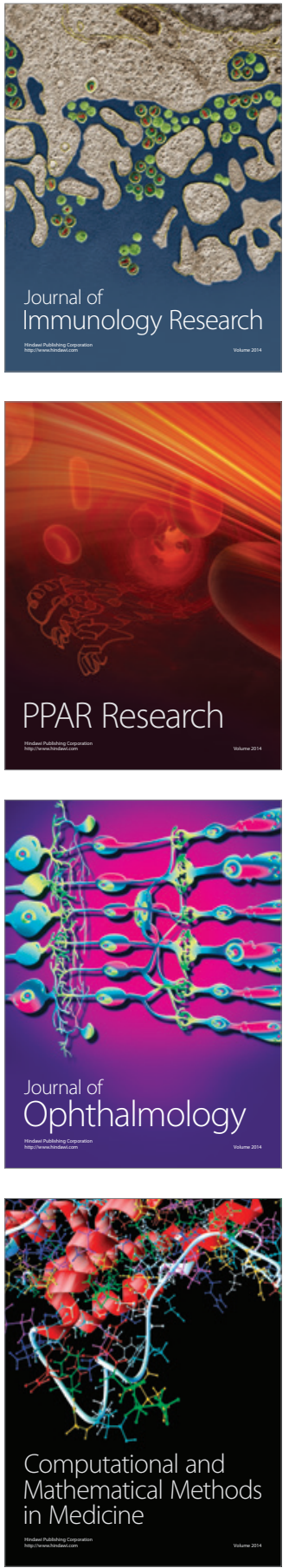

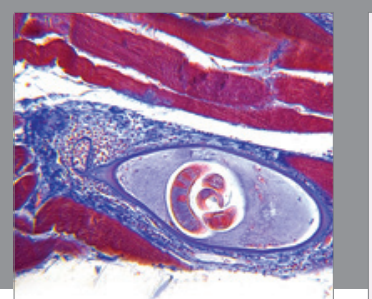

Gastroenterology Research and Practice

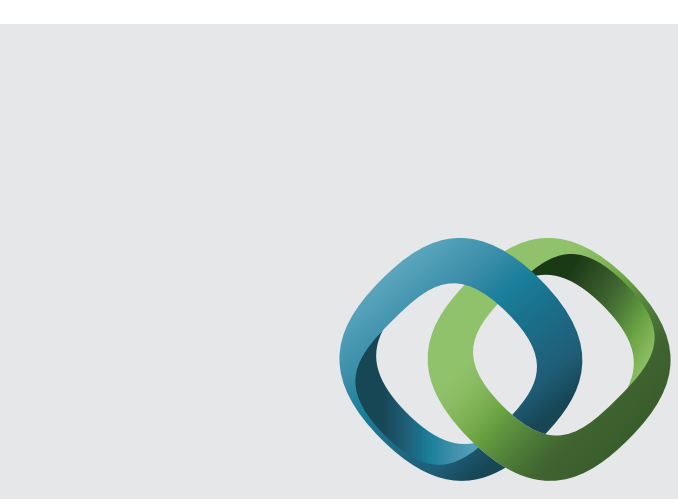

\section{Hindawi}

Submit your manuscripts at

http://www.hindawi.com
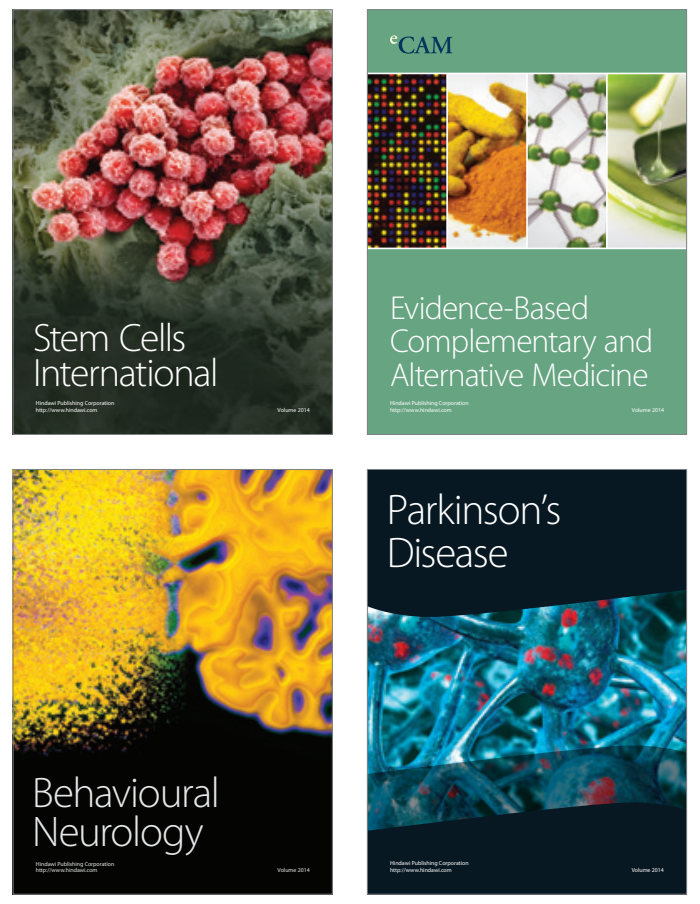
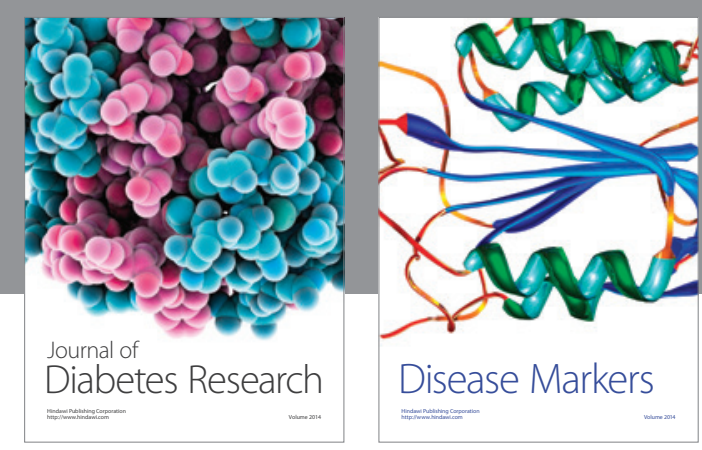

Disease Markers
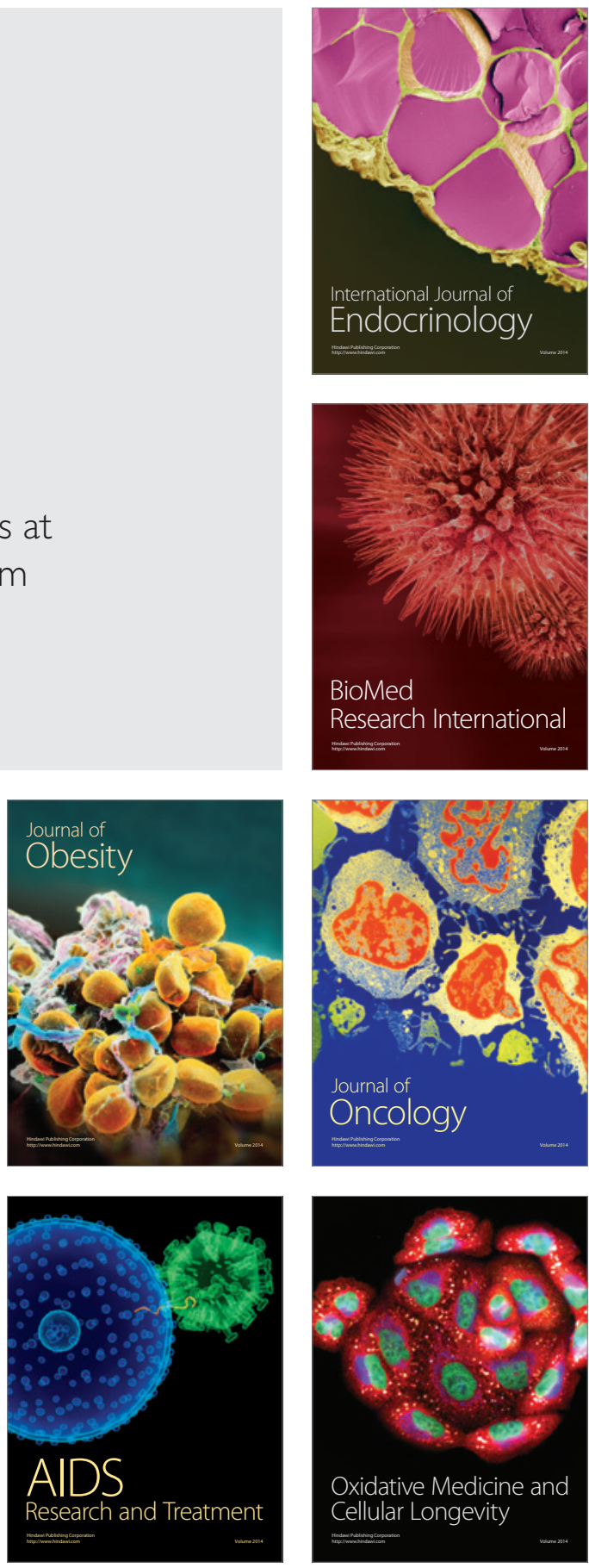